\title{
INFLUÊNCIA DOS INVESTIMENTOS SOCIAIS PARA INCLUSÃO DE EMPRESAS NO ÍNDICE DE SUSTENTABILIDADE EMPRESARIAL (ISE)
}

\author{
Marília Novais da Silva Pereira Martins \\ Mestre em Administração \\ Professora da Universidade Nove de Julho \\ marilianovaisdasilva@gmail.com \\ Anderson L. S. Campos \\ Professor do Programa de Pós-Graduação em Administração \\ Universidade Metodista de São Paulo - UMESP \\ alscampos@uol.com.br \\ Fellipe Silva Martins \\ Doutorando em Administração \\ Universidade Nove de Julho \\ silvamartinsfellipe@gmail.com
}

\begin{abstract}
RESUMO
O processo de seleção de empresas que compõem o Índice de Sustentabilidade Empresarial (ISE) é baseado em sete diferentes dimensões, sendo uma delas a Social. Este trabalho tem por objetivo verificar a capacidade dos investimentos sociais influenciarem a inclusão de uma empresa no ISE. Avaliou-se, por meio de regressão logística, se o volume de gastos sociais, divulgados pelo Balanço Social de uma amostra de 37 empresas, seria capaz de explicar a inclusão da empresa no ISE. Entretanto foram considerados apenas os investimentos sociais discricionários, ou seja, aqueles que não são compulsórios por força de lei. Os resultados sugerem o tamanho da empresa e sua lucratividade como fatores relevantes, enquanto os investimentos sociais não são capazes de explicar a inclusão de uma empresa no ISE.
\end{abstract}

Palavras-chave: ISE; Regressão logística; Responsabilidade social; Sustentabilidade.

\section{INFLUENCE OF SOCIAL INVESTMENTS FOR FIRMS' INCLUSION IN THE CORPORATE SUSTAINABILITY INDEX (ISE)}

\begin{abstract}
The selection process of companies that compose the Corporate Sustainability Index (ISE) is based on seven different dimensions, one being the Social. This work aims to verify the ability of social investments to influence the inclusion of a company in the ISE. We evaluated, using logistic regression, whether the amount of social spending disseminated through social balance of a sample of 37 companies would be able to explain the inclusion of the company in the ISE. However we considered only the discretionary social investments, i.e. those that are not compulsory by law. The results suggest that the size of a company and its profitability are relevant factors, while social investments are not able to explain the inclusion of a company in the ISE.
\end{abstract}

Key words: ISE; Logistic regression; Social responsibility; Sustainability. 


\section{INTRODUÇÃO}

Gestores têm empreendido recursos em estratégias para que suas organizações sejam percebidas como socialmente responsáveis na tentativa de criar valor para seus acionistas. Existem vantagens financeiras, por exemplo, Cheng, Ioannou e Serafeim (2014) encontraram evidências que empresas com maior nível de responsabilidade social corporativa Corporate Social Responsibility (CSR) enfrentam menores restrições de acesso a fontes de financiamento. Dentre outras possibilidades de criação de valor, algumas estão associadas a atração e retenção de mão de obra talentosa (Greening \& Turban, 2000) e ao apelo de marketing de produtos e serviços (Moskowitz, 1972; Fombrun, 1996).

Não tem sido diferente no Brasil, Sartore (2012) afirma que a incidência de menor risco em empresas que tenham políticas claras de adoção do Triple Bottom Line reverte em benefícios palpáveis para tais empresas, dado que o ISE é uma ferramenta de gestão deste risco, ao medir não somente as características de responsabilidade social, mas também basear-se na crença de que tais empresas - devido às suas características intrínsecas bem como à superação dos pré-requisitos para participação no índice - tenham maior rendimento financeiro.

$\mathrm{Na}$ tentativa de obter tais vantagens, há um excessivo uso de termos ligados ao desenvolvimento sustentável e à responsabilidade socioambiental em muitas empresas (e mesmo em organizações sem fins lucrativos) desconectados de medidas e métricas. Isto resulta em um cenário caótico, onde muitas vezes muito se discursa e pouco acontece (Slaper, \& Hall, 2011). A consequência deste cenário é a constatação da publicação de relatórios de sustentabilidade de forma acessória e que são meras aproximações da realidade, uma vez que na verdade indicam a meta e não a conclusão das ações intencionadas (Milne, Kearins, \& Walton, 2006; Milne, Tregidga, \& Walton, 2009; Gray, 2010).

A falta de métricas e padrões faz com que, muitas vezes, as divulgações de políticas sustentáveis por parte de empresas e organizações sejam vistas como meros simulacros, mas também como ações propositadamente orquestradas para colher as benesses de tal posicionamento sem engajamento (Milne, Tregidga, \& Walton, 2009; Gray, 2010). Assim a criação, avaliação e crítica dos índices de avaliação de sustentabilidade são essenciais, uma vez que destes dependem stakeholders internos e externos que confiam e investem ou associam-se a tais empresas (Figliolo, 2010).

O ISE, atualmente, é visto como resultado de excelência corporativa (Silva, \& Quelhas, 2006), e participar deste grupo seleto é um dos objetivos estratégicos buscados por empresas listadas na bolsa.

São avaliadas diversas dimensões para inclusão de uma empresa no ISE. A proposta deste trabalho é investigar se a dimensão social é um fator chave para inclusão de uma empresa no índice. Mais especificamente, se os investimentos sociais voluntários realizados pelas empresas aumentam a probabilidade de ela pertencer a carteira teórica que compõe o ISE.

Este artigo segue com a revisão da literatura, onde também se visita outros trabalhos empíricos, seguido da apresentação da metodologia, a análise dos resultados e os comentários finais.

\section{FUNDAMENTAÇÃO TÉORICA}

Garriga e Melé (2004) propõem uma classificação das diversas teorias sobre CSR em quatro grupos: (i) teorias instrumentais, nas quais a empresa tem uma função econômica bem definida, neste contexto a responsabilidade social é um instrumento para alcançar o objetivo de criação de valor; (ii) teorias políticas, centradas no poder que as empresas possuem na sociedade e o uso responsável deste poder na arena política; (iii) teorias integrativas, nestas as empresas focam no 
atendimento das demandas sociais da sociedade; (iv) teorias éticas, baseadas nas responsabilidades éticas das empresas na sociedade.

Talvez, a divisão mais profunda seja entre as teorias instrumentais e as demais. Elementos das teorias políticas, integrativas e éticas podem ser vistos em diversos trabalhos. Bragato, Siqueira e Graziano (2012) defendem que os gestores empresariais são moralmente responsáveis por elaborar políticas e criar estratégias que girem em torno dos objetivos e dos valores da sociedade. Schroeder e Schroeder (2004) afirmam que as empresas reúnem grande poder, volumes de recursos financeiros e humanos, e por isto têm capacidade de enfrentar problemas estruturais, tais como a fome, violência, doenças e carência de educação formal por meio de atuação social, como uma forma de devolver para a sociedade parte do uso destes recursos humanos, naturais e financeiros em razão do lucro obtido em suas atividades. Perottoni (2002) afirma que a empresa atua com responsabilidade social quando participa diretamente nas ações da comunidade em que está inserida, tornando-a capaz de crescer e permanecer no mercado.

Um representante da teoria instrumental é Jensen (2001) que propõe como objetivo principal da empresa a maximização de valor e o uso da teoria dos stakeholders como apoio para alcançar os resultados econômicos desejados. Trata-se, então, de utilizar a CSR para obter vantagens competitivas que tragam valor para as empresas (Milani Filho, 2008; Baptista, Crispim, \& Pereira, 2011).

A apropriação destas vantagens competitivas só pode ser realizada se houver um disclosure destas ações (Milani Filho, 2008). Uma forma simples e direta de reconhecer quais empresas possuem práticas sustentáveis (e incentivar as demais a desenvolverem) é a inclusão em índices de sustentabilidade (Figliolo, 2010). Em resposta ao interesse dos investidores em relação aos portfólios verdes, a BM\&Fbovespa decidiu pela criação do Índice de Responsabilidade Social e Sustentabilidade Empresarial (ISE) (Tachizawa, \& Andrade, 2008).

O ISE pode ser composto por até 40 empresas, que voluntariamente decidem participar do processo anual de avaliação. O critério para seleção das empresas participantes do ISE foi definido pelo Centro de Estudos de Sustentabilidade da Fundação Getúlio Vargas (Cesfgv) que baseia no conceito do Triple Bottom Line acrescido da avaliação das práticas de governança corporativa. As várias facetas para seleção dos componentes do ISE estão agrupadas em sete dimensões (Figura 1).

\begin{tabular}{|c|l|}
\hline Dimensão & \multicolumn{1}{c|}{ Componentes } \\
\hline $\begin{array}{c}\text { Natureza do } \\
\text { Produto }\end{array}$ & $\begin{array}{l}\text { Impactos pessoais, impactos difusos, princípio da precaução, informação ao } \\
\text { consumidor }\end{array}$ \\
\hline Geral & Compromissos, alinhamento, transparência, corrupção \\
\hline $\begin{array}{c}\text { Governança } \\
\text { Corporativa }\end{array}$ & $\begin{array}{l}\text { Propriedade, Conselho de Administração, auditoria e fiscalização e conduta e } \\
\text { conflito de interesses }\end{array}$ \\
\hline Social & Política, gestão, desempenho, cumprimento legal \\
\hline $\begin{array}{c}\text { Mudanças } \\
\text { Climáticas }\end{array}$ & Política, gestão, desempenho, reporting \\
\hline Ambiental & Política, gestão, desempenho e cumprimento legal \\
\hline $\begin{array}{c}\text { Econômico- } \\
\text { Financeira }\end{array}$ & Política, gestão, desempenho e cumprimento legal \\
\hline
\end{tabular}

Figura 1 - Dimensões do ISE

Fonte: BM\&FBovespa (2014a)

Araújo (2012) ao investigar a diferença entre a compreensão da CSR e sua prática, concluiu que apenas um terço das empresas estudadas entende a Responsabilidade Social Corporativa de forma ampla, incluindo aspectos, tais como sustentabilidade e desenvolvimento das comunidades locais. Outros aspectos evidenciados na pesquisa apontam para a falta de regulação, normatização ou de validação de uma auditoria externa e, por isso, muitas empresas divulgam as informações de acordo com as suas próprias interpretações. Também ficou evidente que muitas confundem a CSR 
com filantropia e ações voluntárias de funcionários e, portanto, há descompassos entre o entendimento do conceito de CSR e o comprometimento das práticas.

Este descompasso sugere que as empresas buscam principalmente vantagens competitivas para criação de valor. Trabalhos como o de Andrade et al. (2013) buscam investigar a relação entre geração de valor e práticas de CSR (pertencimento ao ISE), porém ao buscarem quais fatores explicam o ingresso de uma empresa no ISE, consideram apenas variáveis financeiras, tamanho e setor de atividade, mas não buscam indicadores de práticas sociais ou ambientais.

Ainda na busca por associar criação de valor e CSR, Vital, Cavalcanti, Dalló, Moritz e Costa (2009) encontraram evidências de que empresas que compõem a carteira teórica do ISE apresentam melhor desempenho no que tange às vendas e às exportações. Borçato, Yamada e Pereira (2011) demonstraram que as companhias integrantes de índices específicos de sustentabilidade (como o Dow Jones Sustentability Index, o FTSE4 Good Index ou o ISE) apresentam valor de mercado superior ao daquelas empresas que não fazem parte dos índices.

Entre o discurso e a evidenciação, Milani Filho (2008) chegou à conclusão que, embora a CSR seja um tema muito presente nos relatórios anuais, nem todas as empresas que se declaram socialmente responsáveis informam, de modo adequado, os valores financeiros gastos nestas atividades. Sousa (2006) concluiu que, embora a Bolsa de Nova Iorque e a Bovespa pequem no quesito transparência de seus critérios de avaliação e que ambas não divulguem por completo os questionários aplicados, as empresas desejam fazer parte de seus índices.

$\mathrm{O}$ fato de as empresas aumentarem consideravelmente suas despesas para comunicar suas ações e projetos que envolvam CSR, provavelmente, está associado a intenção de melhoria de suas reputações (Hutton et al., 2001). Podendo suscitar as questões sobre a prática de greenwash.

Aparentemente, o processo de seleção das empresas que compõem os índices de sustentabilidade é considerado mais como medida relativa do que absoluta, o que pode levar a diversos questionamentos.

Diante deste cenário, considera-se apropriado investigar se os gastos financeiros discricionários com ações sociais interferem na probabilidade de uma empresa pertencer ao ISE. Optou-se pelos gastos discricionários porque presume-se que uma empresa não deve ser considerada socialmente responsável apenas por cumprir a lei, para isso já há os incentivos negativos (fiscalização e punições legais).

\section{MÉTODO DE PESQUISA}

\subsection{População e amostra}

O ISE, segundo sua metodologia, será composto, no máximo, por 40 empresas (com pontuação cumulativa nos pré-requisitos). Para ser selecionada para o ISE, a empresa precisa ser uma das 200 empresas listadas com maior volume de ações negociadas no ano anterior e ter participado em pregões nos últimos cinco meses (BM\&FBovespa, 2013b). Em 2013, haviam 184 empresas elegíveis - isto é, que atendiam as condições citadas anteriormente - para inclusão no ISE em 2013 (BM\&FBovespa, 2013c). De acordo com o boletim da Bovespa existiam 452 empresas listadas (BM\&FBovespa, 2013d), isto implica que 40,27\% destas têm capacidade teórica, senão interesse, em integrar a carteira do ISE.

Para o cálculo da amostragem, foi utilizado um nível de confiança de $95 \%$ e um erro amostral máximo de $10 \%$ para uma população de 452 empresas listadas na BM\&FBovespa. Em relação ao percentual de verificação do fenômeno, utilizou-se o total de 40 empresas participantes da carteira do ISE em relação às 452 do total listado na BM\&FBovespa $(8,85 \%)$. 
Os dados para a amostragem são:

- $\quad z \alpha_{/ 2}($ grau de confiança $)=1,96(95 \%)$

- $\quad \mathrm{P}$ (percentual de verificação de fenômeno) $=8,85 \%$

- $\quad \mathrm{N}$ (tamanho da população) $=452$

- e (erro máximo da amostra) $=10 \%$

Aplicando-se os valores à fórmula, obtém-se:

$$
n=\frac{1,96^{2} \cdot 0,0885 \cdot(1-0,0885) \cdot 452}{0,1^{2} \cdot(452-1)+1,96^{2} \cdot 0,0885 \cdot(1-0,0885)}=29,07
$$

Dentro das condições citadas, uma amostra aleatória de, no mínimo, 30 empresas seria suficiente para que um fenômeno fosse observado de maneira adequada. No entanto, o processo de amostragem não foi realizado de forma aleatória, mas sim conforme a disponibilidade de informações. Assim, a amostra foi selecionada por conveniência devido ao número limitado de empresas que publicam balanços sociais o modelo do Ibase.

Espera-se que empresas pertencentes (ou postulantes) ao ISE mantenham políticas sociais consistentes ao longo do tempo, por isso adotou-se os anos de 2011 e 2012 como referência. Corrobora com esse fato, as carteiras do ISE de 2011 e 2012 serem praticamente idênticas, com exceção da saída da Vivo e da Indústrias Romi e da entrada da CCR e da Ecorodovias (BM\&FBovespa, 2014b), por esta razão, foi proposital a exclusão destas empresas da amostra.

Uma vez que a participação no ISE não obriga as empresas participantes a escolherem um ou outro padrão de disclosure, houve um grande limitador na obtenção de respostas válidas para este estudo, de acordo com o padrão utilizado. Confirmando a tendência detectada por Freire, Fontana e Pereira (2011), continuou-se a observar um declínio na utilização do Balanço Social conforme o modelo Ibase comparado com um aumento na adoção do GRI.

Enquanto as tendências de diminuição no Ibase e aumento no GRI se mostraram verdadeiras, há uma área de transição de empresas que optam por explicitar seus investimentos em sustentabilidade, incluindo mais de um formato (Ibase e GRI; Ibase e NBCT; Ibase, GRI e NBCT; etc.). Entre as empresas que se encontram na carteira do ISE, com exceção das empresas não utilizadas pelos motivos supracitados, pode-se constatar o emprego do modelo Ibase por 20 empresas (aproximadamente 52\%), sendo que algumas apresentaram tanto o modelo Ibase quanto o GRI.

No tocante às empresas fora da carteira do ISE, a tendência de utilização do (e/ou substituição do Ibase pelo) GRI se mostrou ainda mais acentuada. Foram computadas 20 empresas não participantes na carteira do ISE, de forma a manter a proporção entre ISE e não-ISE. Assim, o total de empresas utilizadas neste estudo é de 40, aproximadamente $9 \%$ do total de empresas listadas na Bovespa em 2012. Como as variáveis financeiras selecionadas não se mostram adequadas para avaliação de bancos, foram retiradas da amostra duas empresas do grupo ISE e uma do grupo não-ISE, deixando a amostra final com 37 empresas.

\subsection{Coleta de dados}

Foram coletadas informações relativas aos balanços sociais, patrimoniais e demonstrações dos resultados dos exercícios de 2011 e 2012 das 37 empresas, cumprindo-se assim quantidade mínima necessária para a realização da metodologia proposta (18 empresas para o grupo ISE e 19 empresas para o grupo não-ISE, com dados para 2011 e 2012). 
A base deste estudo é a dimensão social e seu impacto no engajamento de empresas com a sustentabilidade e seu retorno por meio da obtenção de classificação favorável ao ISE. O construto dimensão social parte da mensuração de investimentos sociais que a organização empreende. Esta mensuração se dá por meio de dois subconjuntos: os indicadores sociais internos e externos.

Os indicadores sociais internos têm por objetivo medir o comprometimento da empresa ou organização com sua estrutura e stakeholders internos. A mensuração deste subconjunto se dá pelos itens compulsórios (encargos sociais, investimentos em segurança e saúde obrigatórios, etc.) e voluntários (demais itens que a empresa decida investir). Para este trabalho, foram excluídos os itens compulsórios por dois motivos principais: a) não são opcionais, isto é, a empresa não faz por vontade própria, e b) os itens compulsórios variam conforme o setor de atividade da empresa, por exemplo, uma empresa de mineração terá provavelmente mais gastos com segurança e salubridade do que empresas de comércio varejista. Assim, a exclusão de tais itens tem o propósito de igualar as empresas na sua avaliação.

Por sua vez, os indicadores sociais externos são divididos de forma parecida - dividem-se em 'contribuições para a sociedade' (investimento voluntário) e 'tributos' (gastos que tenham impacto na sociedade, administrados pelo governo competente que os recebe e excluídos os encargos sociais, pertencentes aos indicadores internos). Deve-se ressaltar que os investimentos feitos de modo voluntário são os que mais chamam atenção para as ações da empresa, bem como são os que mais obtêm alcance fora desta, sendo o foco deste trabalho. Machado e Machado (2013) também adotaram a prática de expurgar gastos compulsórios para avaliar a influência dos gastos sociais no desempenho financeiro.

\begin{tabular}{|c|c|c|}
\hline Dimensão & Variável & Construção \\
\hline \multirow{3}{*}{$\begin{array}{l}\text { Indicadores de } \\
\text { investimento social }\end{array}$} & GSI & $\begin{array}{l}\text { Média dos indicadores sociais internos (apenas valores } \\
\text { discricionários) como percentagem da receita líquida }\end{array}$ \\
\hline & GSE & $\begin{array}{l}\text { Média dos indicadores sociais externos (apenas valores } \\
\text { discricionários) como percentagem da receita líquida }\end{array}$ \\
\hline & GST & $\begin{array}{l}\text { Média da soma dos indicadores sociais internos e externos } \\
\text { (apenas valores discricionários) como percentagem da receita } \\
\text { líquida }\end{array}$ \\
\hline \multirow{4}{*}{$\begin{array}{l}\text { Indicadores } \\
\text { financeiros }\end{array}$} & LIQ & $\begin{array}{l}\text { Média do quociente do ativo circulante pelo passivo } \\
\text { circulante }\end{array}$ \\
\hline & END & Média do quociente do passivo pelo ativo total \\
\hline & MLB & Média do quociente do EBIT pela receita de vendas \\
\hline & ROE & Média do quociente do lucro pelo patrimônio líquido \\
\hline Variável de controle & TAM & Média do logaritmo natural do ativo total \\
\hline
\end{tabular}

Figura 2 - Variáveis

Fonte: Elaboração própria

Nota: GSI são os Gastos Sociais Internos, GSE são os Gastos Sociais Externos, GST são os Gastos Sociais Totais, LIQ é a Liquidez Corrente, END é o Endividamento, MLB é a Margem de Lucro Bruto, e ROE é o Retorno sobre o Patrimônio Líquido, TAM é Tamanho da empresa.

Em relação aos dados utilizados a partir do relatório Ibase, foram coletados os indicadores sociais internos e externos como percentual sobre a receita líquida. A média dos dois anos deram origem a duas variáveis: Gastos Sociais Internos (GSI), Gastos Sociais Externos (GSE), bem como uma variável que une (soma) os dois conceitos: Gastos Sociais Totais (GST).

No que tange à dimensão financeira, foram selecionadas variáveis financeiras tradicionalmente utilizadas na avaliação de desempenho financeiro. De acordo com Iudícibus (2010), é por meio da extração de significado dos índices financeiros que se compreende a real 
situação financeira de uma empresa, cuja avaliação é geralmente feita levando-se em conta os índices de liquidez, endividamento e rentabilidade (Kaplan, \& Norton, 1992; Barney, \& Hesterly, 2007; Nikbakht, \& Gropelli, 2010).

Deste modo, as variáveis financeiras a serem empregadas são a Margem de Lucro Bruto (MLB), o Índice de Liquidez Corrente (LIQ), o Endividamento total (END), o Tamanho da empresa (TAM) e o Retorno sobre o patrimônio líquido (ROE). O uso destas variáveis permite uma compreensão equilibrada a respeito da situação da empresa e a forma como investidores extraem dados para avaliá-la. A figura 2 descreve os indicadores escolhidos, suas siglas e variáveis.

\subsection{Abordagem de análise dos dados}

A regressão logística é geralmente usada para prever o comportamento de uma variável categórica, que se apresenta na maioria dos casos de forma dicotômica (variável dependente), e possui uma maior flexibilidade quanto ao tipo de variáveis independentes: categóricas e/ou contínuas. Seu resultado final é a função da probabilidade de que um caso ou observação se encontre em uma ou outra categoria, dados os pesos internos das variáveis independentes (Gnanadesikan, 2011).

Neste caso, busca-se relacionar a probabilidade de a empresa pertencer ao ISE com a probabilidade de não pertencer (não ISE) dado um conjunto de variáveis explicativas:

$$
\ln \left(\frac{\pi(I S E)}{1-\pi(I S E)}\right)=\beta_{0}+\beta_{1} G S+\beta_{2} L I Q+\beta_{3} M L B+\beta_{4} E N D+\beta_{5} R O E+\beta_{6} T A M
$$

\section{Onde:}

- $\quad \pi($ ISE) é a probabilidade da empresa pertencer ao grupo ISE;

- GS representa os indicadores de Gastos Sociais (GSI, GSE e GST)

A seguir, são apresentados e discutidos os resultados.

\section{RESULTADOS}

Há diferenças essenciais entre os dois grupos, por exemplo, as empresas participantes do ISE detêm uma parcela muito significativa dos negócios registrados na Bovespa. Este grupo foi responsável pelo valor de mercado de $\mathrm{R} \$ 934,5$ milhões em 2011 (42,15\% do total das ações negociadas durante o ano) e de R \$ 1,02 trilhão em 2012 (42,70\% do total anual) (BM\&FBovespa, 2013c; BM\&FBovespa, 2014b).

A Tabela 1 apresenta as estatísticas descritivas das empresas ISE, não ISE e do total da amostra. Percebe-se que a média de investimento nas variáveis de dimensão social (GSI, GSE e GST) é maior no grupo de empresas fora do ISE do que no grupo ISE. Esta compreensão parece conflitante porque seria de se esperar que as empresas que integram a carteira do ISE tivessem um maior comprometimento com causas sociais, fato que se traduziria também em termos de investimento financeiro. Pode-se observar também que o desvio-padrão das variáveis com gastos sociais também é maior no grupo não-ISE, caracterizando uma grande dispersão destes gastos entre os integrantes deste grupo. Ainda se observa, em ambos os grupos, empresas com investimento social discricionário nulo ou próximo de zero. 
As estatísticas descritivas também sugerem que participantes do grupo ISE obtêm índices melhores de lucratividade (MLB) e de rentabilidade (ROE), mas também possui um nível de endividamento (Endiv) superior. Entretanto, o grupo não-ISE demonstra ter uma situação de liquidez consideravelmente melhor do que o grupo ISE.

Tabela 1 - Estatísticas descritivas

\begin{tabular}{|c|c|c|c|c|c|c|c|c|c|}
\hline & & GSI & GSE & GST & LIQ & MLB & \begin{tabular}{|l|} 
ENDIV \\
\end{tabular} & ROE & TAM \\
\hline \multirow{8}{*}{$\begin{array}{l}\text { Não } \\
\text { ISE }\end{array}$} & $\mathrm{N}$ & 19 & 19 & 19 & 19 & 19 & 19 & 19 & 19 \\
\hline & édia & $3,7 \%$ & $1,6 \%$ & $5,3 \%$ & 1,53 & $16,94 \%$ & 0,51 & $13,9 \%$ & 14,36 \\
\hline & Mediana & $3,1 \%$ & $0,3 \%$ & $3,5 \%$ & 1,50 & $17,26 \%$ & 0,52 & $13,1 \%$ & 14,70 \\
\hline & D. Padrão & $3,1 \%$ & $2,8 \%$ & $3,7 \%$ & 0,45 & $13,74 \%$ & 0,17 & $8,6 \%$ & 2,26 \\
\hline & ínimo & $0,0 \%$ & $0,0 \%$ & $0,2 \%$ & 0,77 & $10,10 \%$ & 0,13 & $-1,2 \%$ & 10,00 \\
\hline & Iáximo & $13,3 \%$ & $9,1 \%$ & $13,8 \%$ & 2,32 & $50,00 \%$ & 0,76 & $31,5 \%$ & 19,38 \\
\hline & Assimetria & 1,88 & 2,01 & 0,86 & 0,10 & 0,60 & $-0,60$ & 0,26 & 0,12 \\
\hline & & 4,20 & 2,65 & $-0,05$ & $-1,03$ & 1,50 & 0,30 & $-0,15$ & 0,43 \\
\hline \multirow{8}{*}{ ISE } & $\mathrm{N}$ & 18 & 18 & 18 & 18 & 18 & 18 & 18 & 18 \\
\hline & $\mathfrak{a}$ & $2,6 \%$ & $1,4 \%$ & $3,9 \%$ & 1,28 & $24,0 \%$ & 0,58 & $15,9 \%$ & 15,93 \\
\hline & ana & $2,2 \%$ & $0,4 \%$ & $3,5 \%$ & 1,17 & $20,5 \%$ & 0,56 & $12,4 \%$ & 16,13 \\
\hline & D. Padrão & $1,9 \%$ & $2,3 \%$ & $3,3 \%$ & 0,43 & $19,9 \%$ & 0,11 & $10,9 \%$ & 1,03 \\
\hline & Mínimo & $0,5 \%$ & $0,0 \%$ & $0,7 \%$ & 0,60 & $1,8 \%$ & 0,42 & $1,3 \%$ & 14,26 \\
\hline & no & $8,4 \%$ & $7,2 \%$ & $15,6 \%$ & 2,33 & $69,4 \%$ & 0,78 & $46,5 \%$ & 17,75 \\
\hline & & 1,86 & 1,93 & 2,73 & 0,89 & 1,44 & 5 & 1,43 & 0,04 \\
\hline & & 4,94 & 2,68 & 9,13 & 0,80 & 1,28 & $-0,91$ & 2,39 & $-1,00$ \\
\hline \multirow{8}{*}{ Tota } & $\mathrm{N}$ & 37 & 37 & 37 & 37 & 37 & 37 & 37 & 37 \\
\hline & Média & $3,1 \%$ & $1,5 \%$ & $4,6 \%$ & 1,41 & $20,4 \%$ & 0,54 & $14,9 \%$ & 15,12 \\
\hline & $\mathrm{N}$ & $2,4 \%$ & $0,4 \%$ & $3,5 \%$ & 1,31 & $17,9 \%$ & 0,55 & $12,6 \%$ & 15,08 \\
\hline & D. Padrão & $2,6 \%$ & $2,5 \%$ & $3,5 \%$ & 0,45 & $17,1 \%$ & 0,15 & $9,7 \%$ & 1,92 \\
\hline & Mínimo & $0,0 \%$ & $0,0 \%$ & $0,2 \%$ & 0,60 & $-10,1 \%$ & 0,13 & $-1,2 \%$ & 10,00 \\
\hline & Máximo & $13,3 \%$ & $9,1 \%$ & $15,6 \%$ & 2,33 & $69,4 \%$ & 0,78 & $46,5 \%$ & 19,38 \\
\hline & Assimetria & 2,12 & 1,96 & 1,54 & 0,42 & 1,36 & $-0,69$ & 1,06 & $-0,60$ \\
\hline & Curtose & 5,72 & 2,52 & 2,20 & $-0,68$ & 2,19 & 0,53 & 1,83 & 0,89 \\
\hline
\end{tabular}

Fonte: Elaboração própria

Nota: GSI são os Gastos Sociais Internos, GSE são os Gastos Sociais Externos, GST são os Gastos Sociais Totais, LIQ é a Liquidez Corrente, END é o Endividamento, MLB é a Margem de Lucro Bruto, e ROE é o Retorno sobre o Patrimônio Líquido, TAM é Tamanho da empresa.

$\mathrm{Na}$ amostra como um todo, nota-se que o volume de verbas discricionárias destinadas ao público interno e externo são bastante diferentes, sendo que os investimentos internos representam aproximadamente o dobro da média dos externos. Isso pode se dever a diversos fatores, desde uma preocupação com os funcionários até dificuldades burocráticas e legais para apoiar ou executar projetos externos a empresa.

Ao se analisar as correlações, verifica-se uma correlação relativamente alta entre os gastos sociais internos (GSI) e externos (GSE) com os gastos sociais totais (GST), mas este efeito é 
resultante do processo de construção da variável GST. Já a correlação negativa entre os gastos sociais externos (GSE) e liquidez (LIQ) contraria o esperado, pois se supõe que empresas com melhor saúde financeira concentrem maiores esforços na área social. Entretanto, se esta liquidez for resultado de uma preocupação com a solvência da empresa devido a uma baixa geração de caixa, esta correlação negativa faria sentido. A relação negativa entre liquidez (LIQ) e lucratividade (MLB) suporta esta segunda interpretação, pois sugere que empresas com maior capacidade de geração de caixa operacional necessita manter um volume menor de recursos para fazer frente aos seus compromissos de curto prazo.

Tabela 2 - Correlação de Person

\begin{tabular}{|c|c|c|c|c|c|c|c|c|}
\hline & GSI & GSE & GST & LIQ & MLB & ENDIV & ROE & TAM \\
\hline GSI & 1 & & & & & & & \\
\hline GSE & $\begin{array}{l}-0,070 \\
(0,679)\end{array}$ & 1 & & & & & & \\
\hline GST & $\begin{array}{c}\mathbf{0 , 6 9 6} \\
(0,000)\end{array}$ & $\begin{array}{c}\mathbf{0 , 6 6 7} \\
(0,000)\end{array}$ & 1 & & & & & \\
\hline LIQ & $\begin{array}{c}0,182 \\
(0,280)\end{array}$ & $\begin{array}{c}\mathbf{- 0 , 4 2 8} \\
(0,008)\end{array}$ & $\begin{array}{c}-0,172 \\
(0,308)\end{array}$ & 1 & & & & \\
\hline MLB & $\begin{array}{c}-0,078 \\
(0,645) \\
\end{array}$ & $\begin{array}{c}0,036 \\
(0,831) \\
\end{array}$ & $\begin{array}{c}-0,032 \\
(0,849) \\
\end{array}$ & $\begin{array}{r}\mathbf{- 0 , 4 4 6} \\
(0,006) \\
\end{array}$ & 1 & & & \\
\hline ENDIV & $\begin{array}{l}-0,034 \\
(0,844)\end{array}$ & $\begin{array}{c}0,024 \\
(0,887)\end{array}$ & $\begin{array}{c}-0,008 \\
(0,964)\end{array}$ & $\begin{array}{l}-0,140 \\
(0,409)\end{array}$ & $\begin{array}{c}-0,282 \\
(0,091)\end{array}$ & 1 & & \\
\hline ROE & $\begin{array}{c}0,066 \\
(0,698)\end{array}$ & $\begin{array}{c}0,094 \\
(0,581)\end{array}$ & $\begin{array}{c}0,117 \\
(0,491)\end{array}$ & $\begin{array}{l}-0,300 \\
(0,071)\end{array}$ & $\begin{array}{c}\mathbf{0 , 5 3 2} \\
(0,001)\end{array}$ & $\begin{array}{c}0,084 \\
(0,622)\end{array}$ & 1 & \\
\hline TAM & $\begin{array}{l}-0,159 \\
(0,348)\end{array}$ & $\begin{array}{l}-0,038 \\
(0,821)\end{array}$ & $\begin{array}{c}-0,146 \\
(0,388)\end{array}$ & $\begin{array}{l}-0,176 \\
(0,297)\end{array}$ & $\begin{array}{l}-0,179 \\
(0,290)\end{array}$ & $\begin{array}{c}\mathbf{0 , 3 6 8} \\
(0,025)\end{array}$ & $\begin{array}{l}-0,021 \\
(0,900)\end{array}$ & 1 \\
\hline
\end{tabular}

Fonte: Elaboração própria

Nota: Entre parênteses o nível de significância bicaudal. Em negrito, os valores significantes a 5\%.

GSI são os Gastos Sociais Internos, GSE são os Gastos Sociais Externos, GST são os Gastos Sociais Totais, LIQ é a Liquidez Corrente, END é o Endividamento, MLB é a Margem de Lucro Bruto, e ROE é o Retorno sobre o Patrimônio Líquido, TAM é Tamanho da empresa.

A correlação positiva encontrada entre a margem de lucro bruto (MLB) e a rentabilidade (ROE) é esperada, pois ambos os indicadores sugerem uma geração positiva de resultados econômicos. A literatura de estrutura de capital já sugere uma relação positiva entre endividamento (ENDIV) e tamanho (TAM) por diversas razões: por serem possuírem uma menor assimetria de informações, menor risco, acesso ao mercado, etc.

Para investigar se os investimentos sociais discricionários são relevantes para inclusão de uma empresa no ISE foi utilizada a regressão logística stepwise com a remoção de variáveis pela estatística Wald. Foram realizadas três regressões, uma para cada indicador de investimento social (GSI, GSE e GST), entretanto como os resultados são similares, optou-se por reportar apenas os resultados com a variável GST.

Tabela 3 - Sumário do modelo (Gastos Sociais Totais)

\begin{tabular}{c|c|c|c}
\hline Passo & $\begin{array}{c}-2 \text { verossimilhança } \\
\text { Logarítmica }\end{array}$ & $\begin{array}{c}\text { Cox \& Snell R } \\
\text { quadrado }\end{array}$ & $\begin{array}{c}\text { Nagelkerke R } \\
\text { quadrado }\end{array}$ \\
\hline 5 & $39,75^{\text {a }}$ & 0,267 & 0,357 \\
\hline
\end{tabular}

Fonte: Elaboração própria

Nota: Estimativa terminada na $5^{\text {a }}$ iteração porque as estimativas dos parâmetros mudaram menos que 0,001 . 
Os $\mathrm{R}^{2}$ de Cox-Snell e de Nagelkerke, reportados na Tabela 3, podem ser interpretados da mesma forma como em um $\mathrm{R}^{2}$ em uma regressão múltipla (apesar de que o $\mathrm{R}^{2}$ de Cox-Snell não chegar a 1 em nenhum caso). Desta forma, pode-se notar um efeito moderado na capacidade de predição do modelo obtido.

Tabela 4 - Regressão Logística (Gastos Sociais Totais)

\begin{tabular}{c|l|l|l|c|c|c}
\hline Variáveis & \multicolumn{1}{|c|}{ B } & \multicolumn{1}{c|}{ S.E. } & \multicolumn{1}{|c|}{ Wald } & g.l. & Sig. & $\operatorname{Exp(B)}$ \\
\hline MLB & 0,051 & 0,029 & 3,223 & 1 & 0,073 & 1,053 \\
TAM & 0,759 & 0,313 & 5,896 & 1 & 0,015 & 2,136 \\
Constante & $-12,715$ & 5,106 & 6,202 & 1 & 0,013 & 0,000 \\
\hline
\end{tabular}

Fonte: Elaboração própria

Nota: MLB é a Margem de Lucro Bruto e TAM é Tamanho da empresa.

A correlação entre as variáveis explicativas na regressão é uma possível fonte de multicolinearidade (MLB com LIQ e ROE, e entre TAM e ENDIV), e talvez seja a explicação porque apenas as variáveis MLB e TAM se mostraram significantes.

Um modelo com apenas as variáveis MLB e TAM consegue classificar corretamente aproximadamente $70 \%$ das empresas da amostra, como pode ser conferido na Tabela 5.

Tabela 5 - Classificação da regressão logística

\begin{tabular}{cccc|c}
\hline \multirow{2}{*}{ Observados } & \multicolumn{3}{c}{ Previsto pelo modelo } \\
\cline { 2 - 3 } & \multicolumn{2}{c}{ Empresas } & \multicolumn{1}{c}{$\begin{array}{c}\text { Percentual } \\
\text { de acerto }\end{array}$} \\
\cline { 2 - 4 } & Não ISE & ISE & 68,4 \\
Empres & Não ISE & 13 & 6 & 72,2 \\
as & ISE & 5 & 13 & 70,3 \\
\hline
\end{tabular}

Fonte: Elaboração própria

As variáveis GSI, GSE e GST não se mostraram significantes, ou seja, não foi encontrada relação entre os investimentos sociais discricionários e a probabilidade de inclusão da empresa no ISE. Uma interpretação deste resultado é que a dimensão social tem um peso pequeno para uma empresa pertencer a este grupo, ou pode-se argumentar que a qualidade dos gastos seja mais relevante do que o montante relativo despendido.

Machado et al. (2012), por meio de regressão logística, tentaram identificar a probabilidade de inclusão de uma empresa no ISE com base nos seus gastos sociais (interno e externo) e ambientais. Os autores sugerem que o nível de investimento social externo como fator determinante para a inclusão de uma empresa no ISE. Entretanto, os autores também não distinguiram entre gastos discricionários e não-discricionários, e um importante componente desta categoria (gastos sociais externos) é o pagamento de tributos. No limite, empresas mais rentáveis pagam mais constantemente tributos, e como os autores não incluíram variáveis de controle financeiras, esta poderia ser a explicação para a discrepância entre os resultados.

Além dos valores totais de gastos sociais e ambientais publicados pelo Ibase, Colares et al. (2012) incluíram uma medida de desempenho econômico (ROE) no modelo, mas nenhuma das variáveis apresentou poder explicativo.

Diferentemente, Milani Filho (2008), por meio de testes não-paramétricos, encontrou diferenças entre o nível de gastos sociais de empresas ISE e um grupo formado por empresas com externalidades negativas (setores de fumo, bebidas e armas), porém o autor avaliou o volume total de gastos (discricionários e não-discricionários). 
Utilizando regressão logística, Nunes et al. (2010) avaliaram um conjunto de variáveis (muitas associadas a governança corporativa) com objetivo similar ao aqui proposto, explicar a inclusão ao ISE, e identificaram o tamanho da empresa e o setor de atividade (separado em dois grupos: alto e moderado impacto ambiental) como fatores influentes. Na interpretação dos autores, grandes empresas de setores com alto impacto potencial ao meio ambiente possuem maior visibilidade e, portanto, estão expostas a potenciais custos políticos, o que se traduz em maior atenção as questões de CSR.

Os resultados aqui reunidos não são suficientes para suportar a hipótese que empresas com maiores gastos sociais possuem maior probabilidade de serem inclusos no ISE.

Vale salientar que o volume de gastos está normalizado pelo valor da receita, e como as constituintes do ISE são empresa de maior porte, o volume absoluto dos gastos também deve ser maior dentro deste grupo. Se este for o caso, justifica-se os resultados que indicam que empresas maiores e mais lucrativas têm maior chance de participar do ISE.

\section{CONSIDERAÇÕES FINAIS}

O objetivo norteador deste estudo foi investigar a importância da dimensão social como fator para inclusão de empresas no ISE. Utilizou-se o modelo do Instituto Ibase como padrão de disclosure social, cujo propósito é prover aos seus usuários uma forma concisa, seleta e transparente de comunicar, de que forma a empresa se posiciona a respeito das características formadoras do triple bottom line.

Para efeito de medição do engajamento das empresas em ação sociais (dimensão social), optou-se por considerar apenas os gastos discricionários (ou voluntários) realizados pelas empresas. Analisou-se se os gastos sociais internos (GSI), os gastos sociais externos (GSE) e os gastos sociais totais (GST) seriam capazes de favorecer significativamente a inclusão de empresas no ISE.

A regressão logística evidenciou que os investimentos sociais internos e externos não são relevantes para a inclusão de uma empresa no ISE, resultado similar a Nunes et al. (2010) e Colares et al. (2012). Entretanto, Machado et al. (2012) encontraram evidências que os gastos sociais externos são um fator para inclusão de uma empresa no ISE.

Os resultados indicam que somente a lucratividade (MLB) e o tamanho (TAM) parecem ter alguma capacidade de discriminar as empresas participantes do grupo ISE. O tamanho da empresa também foi apontado como relevante por Nunes et al. (2010). Este pode ser um indicativo que, primeiro, é necessário uma empresa alcançar sucesso econômico para depois realizar investimentos sociais ou engajar-se em atividades de marketing social.

Outra interpretação possível é que empresas de sucesso sejam mais eficientes na aplicação de recursos na área social. Deste modo, pode-se questionar se investir financeiramente em projetos sociais, sem necessariamente ter a preocupação com o bom andamento, alcance e percepção destes, é relevante para a classificação final como ISE e não-ISE.

Estes resultados estão condicionados a alguns aspectos, um destes é de que a tomada do modelo Ibase (apesar de sua tradição e confiabilidade) não seja mais o mais adequado - o que pode ser entendido se comparada sua característica semicontábil em relação às listagens mais subjetivas e qualitativas de outras metodologias como o GRI. Sugere-se, para estudos futuros o emprego misto do Ibase e do GRI ou a adoção do GRI aliado a critérios determinadamente numéricos para avaliações futuras.

Outra possibilidade que pode ser explorada é a ligação entre o desenvolvimento temporal da empresa (de acordo com seu ciclo de vida) e os investimentos sociais. Empresas maduras (normalmente maiores) passaram por um processo de aprendizado, o que pode ter conduzido a uma maior eficiência e eficácia nas estratégias de relacionamento com a sociedade. Assim, recomendamse estudos posteriores de caráter qualitativo na compreensão das diferenças estruturais entre os grupos.

Revista de Gestão Social e Ambiental - RGSA, São Paulo, v. 10, n. 1, p. 58-71, jan./abr. 2016. 
Outro aspecto importante a ser observado é que o ISE não se baseia somente na noção encontrada no triple bottom line. Este conceito é bastante ampliado e conciliado com noções outras aquém do limite estabelecido nele. Esta distinção deve estar clara em futuros estudos, uma vez que os conceitos empregados pela FGV levam em consideração múltiplas características.

Assim, espera-se que este trabalho produza reflexões sobre o investimento social e disclosure no mundo empresarial sobre a quantidade de recursos aplicados versus os resultados alcançados.

\section{REFERÊNCIAS}

Andrade, L. P., Bressan, A. A., Iquiapaza, R. A., \& de Melo Moreira, B. C. (2013). Determinantes de adesão ao índice de sustentabilidade empresarial da BM\&Fbovespa e sua relação com o valor da empresa. Revista Brasileira de Finanças, 11(2), 181.

Araújo, R. G. (2012) (Des)compassos entre entendimento e práticas de responsabilidade social corporativa. Dissertação de Mestrado, Fundação Getúlio Vargas, Rio de Janeiro, RJ, Brasil.

Barney, J. B., \& Hersterly, W. S (2007) Administração estratégica e vantagem competitiva: casos brasileiros. São Paulo: Pearson.

Baptista, J., Crispim, S., \& Pereira, R. S. (2011) Empresas do Índice de Sustentabilidade Empresarial da Bovespa: nível de conhecimento sobre o Protocolo de Kyoto e utilização dos créditos de carbono. Anais do Encontro Nacional de Gestão e Meio Ambiente, São Paulo, SP, Brasil.

BM\&FBovespa (2013a) ISE - Índice de Sustentabilidade Empresarial. Recuperado em 21 de outubro, 2013

de

<http://www.bmfbovespa.com.br/indices/ResumoIndice.aspx? Indice=ISE\&idioma=pt-br>.

BM\&FBovespa (2013b) Metodologia ISE - Índice de Sustentabilidade Empresarial. Recuperado em 21 de outubro, 2013 de <http://www.bmfbovespa.com.br/Indices/download/MetodologiaISE.pdf>.

BM\&FBovespa (2013c) Lista de empresas elegíveis - Carteira do ISE 2014, período base 2013. Recuperado em 21 de outubro, 2013 de <http://www.bmfbovespa.com.br/Indices/download/Listaempresas-elegiveis-ao-ISE-014.pdf>.

BM\&FBovespa (2013d) Boletim Empresas - Ano 12, n. 191. Recuperado em 21 de outubro, 2013 de http://www.bmfbovespa.com.br/empresas/download/Boletim-49-Marco-2013.pdf.

BM\&FBovespa (2014a) Sustentabilidade em Bolsas de Valores. Recuperado em 11 de janeiro, 2014 de <http://www.bmfbovespa.com.br/Indices/download/Apresentacao-ISE.pdf>.

BM\&FBovespa (2014b) BM\&FBovespa divulga nova carteira do Índice de Sustentabilidade Empresarial para 2012. Recuperado em 23 de janeiro, 2014 de <http://www.bmfbovespa.com.br/Indices/download/Nova-carteira-ISE-2012.pdf>.

Bragato, I. R., Siqueira, E.S, \& Graziano, G.O. (2012) Responsabilidade Social: uma possibilidade de conciliação entre o econômico e o social. In: Marcondes, Cavalcanti, \& Farah. (Orgs.). Empreendedorismo - Estratégia de sobrevivência para pequenas empresas. São Paulo: Saraiva.

Cheng, B., Ioannou, I., \& Serafein, G. (2014) Corporate social responsibility and access to finance. Strategic Management Journal, 35(1),1-23.

Colares, A. C. V., Bressan, V. G. F., Lamounier, W. M., \& Borges, D. L. (2012) O balanço social como indicativo socioambiental das empresas do Índice de Sustentabilidade Empresarial da BM\&F Bovespa. Revista de Contabilidade do Mestrado em Ciências Contábeis da UERJ, 17, 83-100. 
Fombrun, C. (1996) Reputation. John Wiley \& Sons, Ltda.

Freire, F. S., Fontana, V. T., \& Pereira, E. M. (2011) Índice de Responsabilidade socioambiental de empresas brasileiras. Revista de Contabilidade da UFBA, 5(2), 20-43.

Garriga, E., \& Melé, D. (2004) Corporate social responsibility theories: Mapping the territory. Journal of business ethics, 53(1-2), 51-71.

Gnanadesikan, R. (2011) Methods for statistical data analysis of multivariate observations. New Brunswick: John Wiley \& Sons.

Gray, R. (2010) Is accounting for sustainability actually accounting for sustainability...and how would we know? An exploration of narratives of organisations and the planet. Accounting, Organizations and Society, 35(1), 47-62.

Greening, D. W., \& Turban, D. B. (2000) Corporate social performance as a competitive advantage in attracting a quality workforce. Business \& Society, 39(3), 254-280.

Hutton, J., Goodman, M., Alexander, J., \& Genest, C. (2001) Reputation management: The new face of corporate public relations? Public Relations Review, 27(3), 247-261

Iudícibus, S. de (2010) Teoria da Contabilidade (10a ed.). São Paulo: Atlas.

Kaplan, R. S., \& Norton, D. P. (1992) The balanced scorecard: measures that drive performance. Harvard Business Review, January-February.

Machado, M. A. V., \& Machado, M. R. (2013) Responsabilidade social impacta o desempenho financeiro das empresas?. ASAA-Advances in Scientific and Applied Accounting, 4(1), 2-23.

Machado, M. A. V., da Silva Macedo, M. Á., Machado, M. R., \& de Siqueira, J. R. M. (2012) Análise da relação entre investimentos socioambientais e a inclusão de empresas no Índice de Sustentabilidade Empresarial-(ISE) da BM\&FBovespa. Revista de Ciências da Administração, 14(32), 141.

Milani Filho, M. (2008) Responsabilidade social e investimento social privado: entre o discurso e a evidenciação. Revista de Contabilidade Financeira da USP, 19(47), 89-101.

Milne, M., Kearins, K., \& Walton, S. (2006) Creating adventures in Wonderland: The journey metaphor and environmental sustainability. Organization,13(6), 801-839.

Milne, M., Tregidga, H., \& Walton, S. (2009) Words not actions! The ideological role of sustainable development reporting. Accounting, Auditing and Accountability Journal, 22(8), 12111257.

Moskowitz, M. (1972) Choosing socially responsible stocks. Business and Society Review, 1(1), 7175.

Nunes, J. G., Teixeira, A. J., Nossa, V., \& Galdi, F. C. (2010) Análise das variáveis que influenciam a adesão das empresas ao índice BM\&Fbovespa de sustentabilidade empresarial. BASE-Revista de Administração e Contabilidade da Unisinos, 7(4), 328-340.

Perottoni, M. A. (2002) Balanço Social: responsabilidade, padronização e obrigatoriedade. Revista Brasileira de Contabilidade, 134.

Sartore, M. S. (2012) Estado, mercado e índices de sustentabilidade. Sociedade e Estado, 27(3).

Schroeder, J. T., \& Schroeder, I. (2004) Responsabilidade social corporativa: limites e possibilidades. RAE (eletrônica), 3(1).

Silva, L. S. A., \& Quelhas, O. L. G. (2006) Sustentabilidade empresarial e o impacto no custo de capital próprio das empresas de capital aberto. Gestão \& Produção, 13(3), 385-395. 
Sousa, A. C. C. (2006) Responsabilidade social e desenvolvimento sustentável: a incorporação dos conceitos à estratégia empresarial. Dissertação de Mestrado, Universidade Federal do Rio de Janeiro, Rio de Janeiro, RJ, Brasil.

Tachizawa. T., \& Andrade, R. O. B. (2008) Gestão socioambiental. Estratégias na nova era da sustentabilidade. São Paulo: Campus.

Vital, J. T., Cavalcanti, M. M., Dalló, S., Moritz, G. O., \& Costa, A. M. (2009) A influência da participação no índice de sustentabilidade empresarial (ISE) no desempenho financeiro das empresas. Revista de Ciências da Administração, 11 (24), 11-40.

Data da submissão: 02/09/2015

Data da publicação: 30/04/2016 